\title{
Poor vision among China's rural primary school students: Prevalence, correlates and consequences
}

\author{
Hongmei YI ${ }^{\mathrm{a}}$,* , Linxiu ZHANG ${ }^{\mathrm{a}}$, Xiaochen MA ${ }^{\mathrm{b}}$, Nathan CONGDON ${ }^{\mathrm{c}, \mathrm{d}}$, Yaojiang SHI ${ }^{\mathrm{e}}$, \\ Xiaopeng PANG ${ }^{\mathrm{f}}$, Junxia ZENG ${ }^{\mathrm{f}}$, Lei WANG ${ }^{\mathrm{g}}$, Matthew BOSWELL ${ }^{\mathrm{h}}$, Scott ROZELLE ${ }^{\mathrm{h}}$ \\ a Center for Chinese Agricultural Policy, Institute of Geographical Sciences and Natural Resources Research, Chinese Academy of Sciences, Beijing 100101, China \\ ${ }^{\mathrm{b}}$ Department of Agricultural and Resource Economics, University of CA, Davis 95616, USA \\ c State Key Laboratory and Division of Preventive Ophthalmology, Zhongshan Ophthalmic Center, Sun Yat-sen University, Guangzhou 510275, China \\ d ORBIS International, NY 10018, USA \\ e School of Economic Management, Xibei University, Xi'an 710127, China \\ f School of Agricultural Economics and Rural Development, Renmin University of China, Beijing 100872, China \\ g International Business School, Shaanxi Normal University, Xi'an 710062, China \\ h Stanford University, Stanford 94305, USA
}

\section{A R T I C L E I N F O}

\section{Article history:}

Received 29 November 2013

Received in revised form 23 August 2014

Accepted 3 January 2015

Available online 9 January 2015

\section{Jel codes:}

I24

I14

I18

Keywords:

Rural China

Poor vision

Children

Academic performance

Mental health

\begin{abstract}
A B S T R A C T
Using a survey of 19,977 children in two provinces, this paper explores the prevalence, correlates and potential consequences of poor vision among children in China's vast but understudied rural areas. We find that $24 \%$ of sample students suffer from reduced uncorrected visual acuity in either eye and $16 \%$ in both eyes. Poor vision is significantly correlated with individual, parental and family characteristics, with modest magnitudes for all correlates but home province and grade level. The results also suggest a possible adverse impact of poor vision on academic performance and mental health, particularly among students with severe poor vision.
\end{abstract}

(c) 2015 Elsevier Inc. All rights reserved.

\section{Introduction}

A series of World Health Organization-supported studies suggest that approximately 10 to $15 \%$ of school-aged children in the developing world have common vision problems (He, Huang, Zheng, Huang, \& Ellwein, 2007; Maul, Barroso, Munoz, Sperduto, \& Ellwein, 2000; Murthy et al., 2002). Research demonstrates that an even higher share of children (up to 20\%) has vision problems (Pi et al., 2012). In most settings, about $90 \%$ of these vision problems are caused by refractive error (largely myopia, but also hyperopia and astigmatism). The remaining 10\% are caused by amblyopia, pediatric cataract and other less common vision disorders.

\footnotetext{
* Corresponding author at: No. Jia 11, Datun Road, Chaoyang, Beijing 100101, China. Tel.: +86 10 648889885; fax: +86 1064856533.

E-mail addresses: yihm.ccap@igsnrr.ac.cn (H. Yi), lxzhang.ccap@igsnrr.ac.cn (L. Zhang), mxc4068@gmail.com (X. Ma), ncongdon1@gmail.com (N. Congdon), syj8882002@yahoo.com.cn (Y. Shi), pangxp@ruc.edu.cn (X. Pang), zengjunxia@ruc.edu.cn (J. Zeng), wangleiml@snnu.edu.cn (L. Wang), kefka@stanford.edu (M. Boswell), rozelle@stanford.edu (S. Rozelle).
} 
In most cases children's vision problems can be easily detected by simple vision tests (such as visual acuity screenings) and corrected by timely and proper fitting of quality eyeglasses (World Health Organization, 2006). Unfortunately, studies in a variety of developing countries document that 35 to $85 \%$ of individuals with refractive error do not have eyeglasses, and that many of them have never been screened or examined (Bourne, Dineen, Huq, Ali, \& Johnson, 2004; Fotouhi, Hashemi, Raissi, \& Mohammad, 2006; Ramke, Du Toit, Palagyi, Brian, \& Naduvilath, 2007).

In rural areas of China, the prevalence of children with vision problems appears to be higher than in other countries. One study has shown that nearly half of all vision problems among children in the world occur in China (Resnikoff, Pascolini, Mariotti, \& Pokharel, 2008). In a study of junior high school children in Guangdong Province, He et al. (2007) showed that $37 \%$ of 13 -year-old children were myopic. Among 17 -year-olds, this rate increased to $54 \%$. In another study conducted in urban Guangdong, He et al. (2004) demonstrated that nearly half of children between the ages of five and 15 had refractive error. In 2004 Glewee, Park, and Zhao (2011) conducted a study in one of the poorest areas of Chinatwo ethnically Tibetan populated counties in Gansu Province-and found that $13 \%$ of fourth to sixth grade children had poor vision.

Despite the relative ease of correcting the large majority of these vision problems, a significant share of children in China's rural areas who would benefit from refractive correction (by way of properly prescribed eyeglasses) does not appear to be getting care (Congdon et al., 2008). In their studies in rural Guangdong researchers from Zhongshan Ophthalmic Center, Sun Yat-sen University found that, of the junior high school students that were myopic, only 40\% were wearing glasses (He et al., 2007). In another study in rural Guangdong, Li et al. (2010) found that two thirds of children who were informed of their need to wear glasses on the basis of a high quality screening examination failed to obtain them. Glewee et al. (2011) showed that for every 100 children that were myopic, less than three of them were wearing glasses.

While consistently finding uncorrected vision to be a problem in China, research to date has tended to rely upon small regional samples and data that are either dated or whose sampling methodology is not fully made clear. For example, the studies of He et al. (2004, 2007), while using high quality optometric approaches, were carried out in a single area in one of China's fastest growing coastal provinces. The study of Li et al. (2010) was also located in a relatively developed area of China. The work by Glewee et al. (2011), while looking at one of China's poorest areas, is somewhat dated, using data from 2004. China's economy has more than doubled in size since that time and incomes-even in poor rural areas-have risen by nearly $100 \%$, on average (China National Bureau of Statistics, 2012). The exact refraction protocol used in the Glewee et al. (2011) study is also not made clear. The most recent work focused on China's poor western region, Pi et al. (2012), only relies on the data collected from one district of Chongqing municipality.

If up-to-date empirical evidence from large samples on the prevalence of vision problems in rural China is scarce, there is even less information on who has vision problems. There are several studies that report on the correlates of vision problems for children (Congdon et al., 2008; Pi et al., 2012). These studies, however, mostly examine only the correlates of gender and age. Some document myopia-related behavior factors (such as reading, doing homework, and using a computer) without controlling for important environmental factors such as parental characteristics and family background. Importantly studies performed in China have not fully addressed the potential impacts of living environment (living at home versus boarding at school-boarding is a very common phenomenon in rural China) and family circumstances (such as parental education and migration status as well as family wealth) on children's vision. If research could shed more light on those characteristics correlated with poor vision, policy makers might be able to tailor their policies to most efficiently address poor vision among young people in rural areas.

One reason for the relative inattention to the prevalence and correlates of vision problems in China may be the fact that there is not much evidence available on the adverse consequences of poor vision among children. It is well known that if vision problems in adults are left uncorrected, there can be serious consequences. A WHO study estimates that the potential global lost productivity from uncorrected refractive error may be more than one hundred billion dollars annually (Smith, Frick, Holden, Fricke, \& Naidoo, 2009). There are only a handful of studies that examine the potential negative impacts of children's vision problems (Congdon et al., 2008; Esteso et al., 2007; Nilsson, 2007). For example, a study of three to 16 year old children in the UK shows that visual impairment has negative effects on quality of life (Chadha \& Subramanian, 2011). Glewee et al. (2011) document that the grades of students suffer when they need glasses but do not have them.

The goal of this paper is to explore the prevalence, correlates and potential consequences of poor vision among elementary school children in China's rural areas. To meet this goal, we have three specific objectives. First, we document the prevalence of children's vision problems. Second, we identify their correlates. Are certain types of children more prone to poor vision or is it a problem that arises indiscriminately? Finally, we seek to document if there are any adverse academic consequences associated with poor vision. A strength of the current analysis is that we examine the association between vision and academic performance as well as mental health in the context of a large study (both in terms of sample size and area covered). Unfortunately, however, due to the cross sectional nature of the data, we will only be able to establish correlations and not causation.

To achieve these objectives, the rest of the paper is organized as follows. In Section 2 we describe the data. In Section 3 we provide estimates for the prevalence of vision problems in our sample of nearly 20,000 elementary children from more than 250 schools in northwest China. In Section 4 we study the correlates of poor vision problems. In Section 5 we examine the potential consequences of poor vision problems on student academic performance (as measured by a standardized test of math). In Section 6 we examine the potential impact of poor vision on mental health (measured by MHT test). Section 7 summarizes and concludes. 


\section{Data}

The data used in this study come from a survey of 19,977 grade four and grade five students in 253 primary schools in northwest China. ${ }^{1}$ The data were collected during the fall semester of the 2012-13 academic year. To choose our sample of schools, we followed a five-step process. First, we obtained a list of all the schools in two prefectures: Tianshui Prefecture in Gansu Province and Yulin Prefecture in Shaanxi Province. ${ }^{2}$ A map of these regions is provided in Fig. 1. Second, we included all the counties of these two prefectures except for one county in Yulin. ${ }^{3}$ In total, 18 counties were included in the sampling frame-seven counties in Tianshui and 11 counties in Yulin. After selecting the counties, the third step involved obtaining a list of all primary schools from each county's bureau of education. In total, the list included 435 rural schools. Using the list as a guide, we proceeded to the fourth step and randomly selected one school from each township in all of the 18 counties in the sample. We limited our choice of schools to only those schools that had between 50 and 150 students in grades four and five together for implementation efficiency and logistical reasons. ${ }^{4}$ In total our sample schools are representative of $81 \%$ of the students in the prefectures. Finally, within each school, only one class was included in each grade. If there was more than one class in either grade, we randomly selected one class only.

The full sample was more or less balanced between prefectures/provinces (Tianshui and Yulin) and between grades (grade four and grade five). Of the total number of students, 10,309 students were from 120 schools in Tianshui Prefecture; and 9668 students were from 133 schools in Yulin Prefecture. Students were also almost equally distributed between the two grades. In Tianshui Prefecture, 5116 students were in grade four; and 5193 students were in grade five. In Yulin Prefecture, 4749 students were in grade four; and 4919 students were in grade five. ${ }^{5}$

Within each school we collected information on the sample grade four and five students using a survey protocol that included four parts. In the first part, our enumerators (graduate students from Shaanxi Normal University who were trained in enumeration techniques) administered a questionnaire to collect information on student- and family-characteristics of the sample students. The surveys included questions on age, gender, boarding status at school, parental schooling, parental migration status and household assets.

In the second part of the survey protocol students were given standardized math exams. Questions used in the math exam were drawn from a bank of questions that were developed by the Trends in International Mathematics and Science Study (TIMSS) testing service. The TIMSS test is an international assessment of mathematics and science knowledge of primary school students (Provasnik et al., 2012). To ensure coherence with the national curriculum, the test questions were chosen with assistance from educators in the local bureaus of education. We pretested the exam repeatedly to ensure its relevance and make sure that the time limits were appropriate. The exam was timed carefully and proctored closely by two enumerators at each school. For analysis, scores for the standardized math tests are normalized by the distribution of scores in each grade.

In the third part, we used a psychological test of well-being, the Mental Health Test (MHT), to measure children's mental health. ${ }^{6}$ The MHT is a variation of Children's Manifest Anxiety Scale (CMAS) an international standardized test for anxiety in children that is widely used in many countries (Reynolds \& Richmond, 1978; Zhang et al., 2013). The MHT is a 10 minute test that was administered by our enumeration team at the end of our questionnaire. The test contains 100 yes/no questions that measure eight categories of anxiety: learning anxiety, personal anxiety, loneliness anxiety, self-blaming tendency, sensitivity tendency, body anxiety, phobia anxiety, and impulsive anxiety. The larger the MHT score, the larger one's anxiety level and therefore the worse one's mental health is. We standardized the MHT score in order to make our results comparable to other studies (Cohen, 1988; Zhang et al., 2013).

Finally, students also were administered with a visual acuity screening test. The screening test was performed by a team of one optometrist, one nurse and one staff assistant. All of the team members were trained by trainers from Zhongshan Ophthalmic Center, Sun Yat-sen University. Visual acuity was tested separately for each eye at a distance of $4 \mathrm{~m}$ using Early Treatment Diabetic Retinopathy Study (ETDRS) charts. ETDRS charts are accepted as the worldwide standard for accurate visual acuity measurement (Camparini, Cassinari, Ferrigno, \& Macaluso, 2001). The chart has 14 rows of optotypes (represented by capital letter E) with 5 optotypes pointing (randomly) in different directions in each row. The sizes of the optotypes become smaller as one moves from the top of the chart to the bottom. Visual acuity (VA) is recorded as 6/X, in which X varies between 60 (at the very top) and three (at the very bottom) when

\footnotetext{
${ }^{1}$ We chose fourth and fifth grade students for our sample because our ophthalmologist consultants at Sun Yat-sen University point out that the onset of myopia typically begins at age 8 to 10, which coincides with fourth and fifth grade in rural Chinese schools (see also: Zhao, Pan, Sui, Munoz, Sperduto \& Ellwein, 2000).

2 A prefecture is an administrative division in China that is larger than both a township and county division but smaller than a province division.

3 One county was excluded because of its small population size. The population in this county is only 80,000 whereas the average population of the other 11 counties in Yulin enrolled in our study is 300,000 . The fixed costs in the survey process of adding such a small county prevented us from choosing this county.

4 This limitation was imposed mainly for reasons of implementing efficiency and the logistical requirement that we screen one entire school per day. For statistical power reasons, we needed the sample schools to have, on average, 15 students with poor vision. We began with the assumption (following Glewee et al., 2011) that $15 \%$ of the children in the school had poor vision. This means that we needed, on average, 100 students in grades 4 and 5 per school. In order to provide consistently high quality visual acuity measurement, at most, only 150 grade four and five students could be given a screening test per school each day. This put a cap of 150 on the number of students in grades 4 and 5 per school. Thus, we limited our choice of schools to those with 50 to 150 students in grades four and 5 , yielding roughly 100 grade four and grade five students per school. Because of this restriction, 85 schools were eliminated from the sampling choice. Only $7 \%$ of schools had fewer than 50 students in grades four and 5; only $12 \%$ of schools had more than 150 students. In total our sample schools are representative of more than $80 \%$ of the students in the prefectures.

5 In general, our data had few missing values. In total, we only found 475 missing values for all variables used in the analysis. This means that we had missing values for less than $0.2 \%$ of all values $(=475 /(19,977 * 14) * 100 \%)$. In the regressions, we replaced the missing value with the mean of the corresponding variable. If we ran the regressions with and without missing values, the results are the same.

${ }^{6}$ To the best of our knowledge, the research exploring the relationship between childhood mental health and poor vision is limited. However, what evidence does exist suggests that anxiety among primary students with vision problems could be a concern. Liu, Li, Yuan, and Yu (2012) used the Symptom Rating Scale (SCL-90) to measure the mental health of high school students and find that the mental health of myopic students was significantly worse than mild and moderate myopia students, particularly regarding anxiety, depression, and interpersonal sensitivity. To shed more light on this important correlation, we chose to include an anxiety metric in our study.
} 


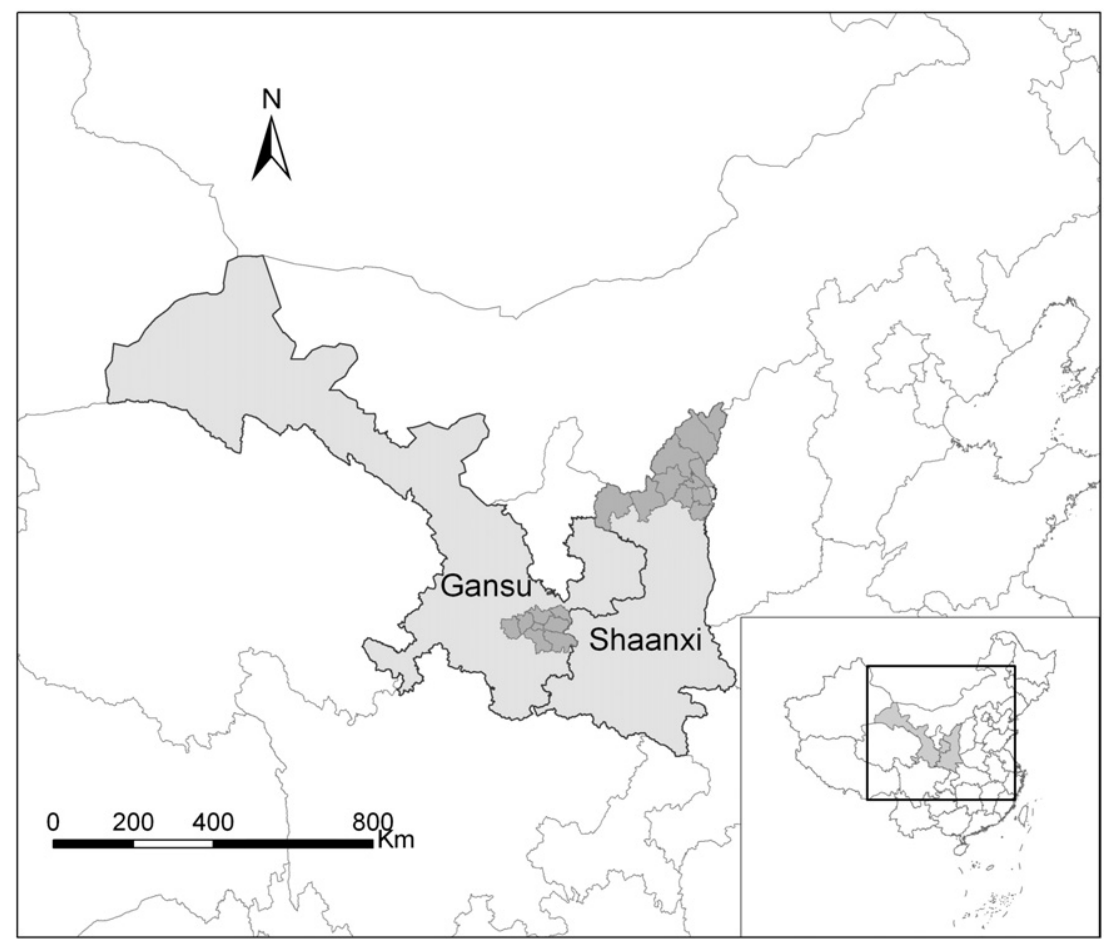

Fig. 1. Survey regions.

tested at a distance of $4 \mathrm{~m}$. Each student started testing from the top row (6/60). If the orientation of at least four of the five optotypes was correctly identified the student was re-examined on row 4 (6/30). If one or no optotypes was missed on row 4 the testing resumed at row $7(6 / 15)$ continuing to row $11(6 / 6)$. A failure was defined as an inability to correctly identify the orientation of at least four of the five optotypes in a given row. The row immediately above the failed row was tested until the student identified at least four of the five optotypes in a row. The lowest row read successfully was assigned as the visual acuity for the eye undergoing testing. If the top row was missed at $4 \mathrm{~m}$, the student was advanced to $1 \mathrm{~m}$ with progression down the chart as described above and the visual acuity recorded was divided by four. The meaning of the visual acuity fraction $6 / \mathrm{X}$ is that the subject can correctly identify at a distance of $6 \mathrm{~m}$ what a normal person can see at X meters.

Table 1 describes the ranges of visual acuity and the visual notations used in this paper. By the convention of the ophthalmology field (Cumberland, Peckham, \& Rahi, 2007; He et al., 2004), reduced uncorrected visual acuity is defined as visual acuity less than or equal to 6/12 in either eye (column 1). Reduced uncorrected visual acuity is widely used as a proxy for myopia or indicative of visual impairment (Luo et al., 2006; Tong et al., 2002; Wedner, Ross, Balira, Kaji, \& Foster, 2000). Following common practice in the literature (Congdon et al., 2008; He et al., 2004, 2007), we also report visual acuity results based on the better eye. ${ }^{7}$ We define poor vision as uncorrected visual acuity less than 6/12 in the better eye, which means both of the student's eyes having uncorrected visual acuity less than 6/12 (column 2). In addition, to facilitate the analysis in the rest of the paper, a set of progressively stricter cutoffs for poor vision is defined as follows (column 3). Mild poor vision is defined as visual acuity less than $6 / 12$ but greater than or equal to $6 / 24$; moderate poor vision is defined as visual acuity less than $6 / 24$ but greater than or equal to 6/48; severe poor vision is defined as visual acuity less than $6 / 48$ in the better eye. To provide an intuitive comparison of what our cut-offs mean (e.g., the cutoffs for severe poor vision), the WHO's standard of blindness is defined as visual acuity less or equal to 6/120 in both eyes with the best correction possible (WHO, 2012). In the U.S., the standard of blindness is visual acuity less or equal to 6/60 in the better eye with the best correction possible (American Foundation for the Blind, 2002). Hence, when we say severe poor vision we are talking about individuals that have significant difficulty in seeing (without correction). The sight of individuals with severe poor vision, however, is not to be considered blind (as defined by the WHO or the U.S. government's health officials).

As described above, the levels of poor vision when defined using measures from visual acuity charts (mild poor vision; moderate poor vision; severe poor vision) are discrete, not continuous (Table 1, column 4). In order to calculate and compare different visual acuity levels in a number of our exercise in the rest of this paper, we require a linear scale with constant increments (Bailey \& Lovie, 1976; Grosvenor, 2007). In the field of ophthalmology/optometry LogMAR is one of the most commonly used continuous scales. This scale uses the logarithm transformation: e.g., LogMAR $=\log 10($ MAR). In this definition, the variable, MAR, is short for Minimum Angle of Resolution, which is defined as the inverse of visual acuity, e.g., MAR $=1$ / VA. LogMAR offers a relatively intuitive

\footnotetext{
${ }^{7}$ The fact that the ophthalmology literature report results based on the better eye is due to fact that the visual acuity of the better-seeing eye is the best indication of an individual's level of vision. A person blind in one eye but with normal vision in the other is able to perform most visual tasks, except those requiring fine stereo vision (perception of depth) as well as a normally-sighted person.
} 
Table 1

Visual acuity ranges and notations.

Data source: Authors' survey.

\begin{tabular}{|c|c|c|c|c|c|}
\hline \multicolumn{3}{|l|}{ Notations based on: } & \multicolumn{3}{|c|}{ Visual acuity ranges } \\
\hline & $(2)$ & (3) & $(4)$ & $(5)$ & (6) \\
\hline Either eye & Better eye & Better eye & VA & MAR & LogMAR \\
\hline \multirow[t]{6}{*}{ Normal vision } & Normal vision & Normal vision & $6 / 3$ & 0.5 & -0.3 \\
\hline & & & $6 / 3.8$ & 0.63 & -0.2 \\
\hline & & & $6 / 4.8$ & 0.8 & -0.1 \\
\hline & & & $6 / 6$ & 1.0 & 0 \\
\hline & & & $6 / 7.5$ & 1.25 & 0.1 \\
\hline & & & $6 / 9.5$ & 1.6 & 0.2 \\
\hline \multirow[t]{15}{*}{ Reduced uncorrected visual acuity } & Poor vision & Mild poor vision & $6 / 12$ & 2.0 & 0.3 \\
\hline & & & $6 / 15$ & 2.5 & 0.4 \\
\hline & & & $6 / 19$ & 3.2 & 0.5 \\
\hline & & & $6 / 24$ & 4 & 0.6 \\
\hline & & Moderate poor vision & $6 / 30$ & 5 & 0.7 \\
\hline & & & $6 / 38$ & 6.3 & 0.8 \\
\hline & & & $6 / 48$ & 8 & 0.9 \\
\hline & & Severe poor vision & $6 / 60$ & 10 & 1.0 \\
\hline & & & $6 / 76$ & 12.5 & 1.1 \\
\hline & & & $6 / 96$ & 16 & 1.2 \\
\hline & & & $6 / 120$ & 20 & 1.3 \\
\hline & & & $6 / 152$ & 25 & 1.4 \\
\hline & & & $6 / 192$ & 32 & 1.5 \\
\hline & & & $6 / 240$ & 40 & 1.6 \\
\hline & & & $<6 / 240$ & & \\
\hline
\end{tabular}

\section{Note:}

a. There are only 14 rows printed in ETDRS Chart, ranging from 6/3 to 6/60. An individual who cannot see the top row at a distance of 4 m will be advanced to 1 m, and his/her visual acuity will be recorded by dividing by 4 . For example, if a student can only see the top row at $1 \mathrm{~m}$, the visual acuity is $6 / 240$. If the top row is still missed at $1 \mathrm{~m}$, the visual acuity is recorded as $<6 / 240$.

b. MAR is short for Magnification Requirement, which is defined as the inverse of visual acuity, e.g., MAR $=1 /$ VA.

c. $\log M A R=\log 10(M A R)$.

interpretation of visual acuity measurement. It has a constant increment of 0.1 across its scale; each increment indicates approximately one line of visual acuity loss (in the ETDRS chart). The higher the LogMAR value, the worse one's vision is.

Table 2 presents descriptive statistics for the students in the sample. As noted above, the full sample was more or less equally distributed between prefectures/provinces and between grades four and five. Specifically, $48 \%$ of the students were from Shaanxi and $52 \%$ of the students from Gansu (row 1); and $49 \%$ of the students in grade four and $51 \%$ of the students in grade five (row 2 ). In our sample, $48 \%$ of the students were female and $52 \%$ were male (row 3), a ratio similar to those found in most poor areas in China (CNBS, 2012) due to selective male birth. The average age is 10.6 (or ten years, seven months), which suggests that students started primary school (grade 1), on average, at the age of 7 (row 4). Of all students in the sample schools, $18 \%$ of them are in boarding schools (row 5); $12 \%$ of the students live without their parents at home (with a caregiver, typically paternal grandparents-row 6). Seven percent of fathers never went to school (row 7). The rate of never attending school increased to $22 \%$ for mothers (row 8 ). Only $9 \%$ of mothers and $13 \%$ of fathers attended school for 12 years or more (rows 9 and 10).

Given our sampling strategy, the results of our survey are representative of primary schools in poor areas of northwestern China. According to the CNBS (2012), Gansu Province ranks at the bottom of 31 provincial-level divisions in per capita annual net income of rural residents and Shaanxi Province ranks 26 th. $^{8}$ What is more, in both our sample prefectures, most of the sample counties are poor counties. China has designated 592 out of the nation's 2862 county-level divisions as nationally-designated poor counties (Xinhua, 2011). The threshold for poor county status is an annual per capita income of less than 2300 RMB or about one US dollar per person per day (in Purchasing Power Parity terms). Gansu Province and Shaanxi Province rank number two and three in the nation in terms of the total number of poor counties. In our sample, six out of the seven counties in Tianshui (Gansu) and seven out of the 11 sample counties in Yulin (Shaanxi) are designated as poor counties.

\section{Prevalence of poor vision}

The prevalence of reduced uncorrected visual acuity is high in rural western China. Among the 19,977 grade four and grade five students that were screened, 4849 had visual acuity less than or equal to 6/12 in either eye, a standard indicator of vision problems in children. By this standard, the prevalence of reduced uncorrected visual acuity in the sample is 24\% (Table 3, row 1, column 1). This means that nearly one out of four students in grades four and five in some of the poorest areas of China has poor vision.

Is this rate of prevalence high or low? On the one hand such rates may not be considered high in the context of China. As discussed above, previous research has reported the prevalence of reduced uncorrected visual acuity in China to be among the highest in the

\footnotetext{
8 The national average of per capital annual net income for rural residents is RMB 7917 (or about USD 1274). The number for Gansu is RMB 4507 (or about USD 725 ) and Shaanxi RMB 5763 (or about USD 927).
} 
Table 2

Summary statistics.

Data source: Authors' survey.

\begin{tabular}{|c|c|c|c|}
\hline & & Mean & S.D. \\
\hline \multicolumn{4}{|c|}{ Individual characteristics } \\
\hline$(1)$ & Province $(1=$ Shaanxi) & 0.48 & 0.50 \\
\hline (2) & Grade $(1=$ grade 4$)$ & 0.49 & 0.50 \\
\hline (3) & Gender $(1=$ male $)$ & 0.52 & 0.50 \\
\hline (4) & Age (years) & 10.55 & 1.15 \\
\hline (5) & Boarding status ( 1 = boarding at school) & 0.18 & 0.39 \\
\hline \multicolumn{4}{|c|}{ Parental and family characteristics } \\
\hline (6) & Parental migrant status ( 1 = both parents migrant) & 0.12 & 0.33 \\
\hline (7) & Father illiteracy $(1=$ yes $)$ & 0.07 & 0.25 \\
\hline (8) & Father has education of 12 years or more $(1=$ yes $)$ & 0.13 & 0.34 \\
\hline (9) & Mother illiteracy $(1=$ yes $)$ & 0.22 & 0.41 \\
\hline \multirow[t]{3}{*}{$(10)$} & Mother has education of 12 years or more $(1=$ yes $)$ & 0.09 & 0.28 \\
\hline & Number of schools screened & 253 & \\
\hline & Number of students screened & 19,977 & \\
\hline
\end{tabular}

world-more than 50\% in some studies among older children (Chen, Huang, Rozelle, \& Zhang, 2007, Chen et al., 2014; Congdon et al., 2008). This would mean that our findings are low by comparison. However, the studies of He and Congdon were based on data collected from older students in Guangdong, where rural income levels exceed those of our sample provinces (CNBS, 2012). The international vision care literature has found that vision problems (particularly those due to refractive error) tend to rise with both wealth (Saw et al., 2002; Wensor, McCarty, \& Taylor, 1999; Wong et al., 2000) and age among children (Congdon et al., 2008; Dandona et al., 2002; Goh, Abqariyah, Pokharel, \& Ellwein, 2005; He et al., 2004, 2007). Taking into consideration the fact that our sample is drawn from younger children dwelling in poor areas, the rates we record should not be considered low. In fact, Glewee et al. (2011) found rates of only $13 \%$ in nearby poor rural areas in western China, which would make our $24 \%$ point estimate appear relatively high. Thus, we believe that it is fair to say that our results are somewhat surprising since we find that there is such a high prevalence of reduced uncorrected visual acuity (24\%) among grade four and five children in a poor, rural setting.

Although both of the sample prefectures are in China's poor northwest, the prevalence of reduced uncorrected visual acuity differs between Gansu and Shaanxi provinces (Table 3, row 1, columns 2 and 3). Of the 10,309 students in the sample schools in Gansu Province, 1868 failed their visual acuity screening test, reflecting a prevalence of reduced uncorrected visual acuity of $18 \%$. In contrast, of the 9668 students in Shaanxi Province, 2981 failed, reflecting a 31\% prevalence rate. Hence, while the prevalence of reduced uncorrected visual acuity is high among students in both provinces, it is 13 percentage points (or 72\%) higher in Shaanxi relative to Gansu $(\mathrm{p}<0.01)$.

The prevalence of reduced uncorrected visual acuity among our sample also increases with grade level (Table 3, row 1, columns 4 and 5). Of the 9865 grade four students in our sample, 2070 failed their visual acuity screenings. The prevalence of reduced uncorrected visual acuity for grade four students is $21 \%$. Of the 10,112 grade five students, 2779 failed their visual acuity screenings. The prevalence of reduced uncorrected visual acuity for grade five students is $27 \%$. The prevalence of reduced uncorrected visual acuity in grade five is 6 percentage points (or 29\%) higher than that in grade four $(\mathrm{p}<0.01)$.

While we cannot determine the exact reasons for the differences in prevalence of reduced uncorrected visual acuity between students in Shaanxi and Gansu, and between students in grade four and grade five, neither of these gaps is particularly surprising. Studies using nationally representative data of the United States in the 1970s show that myopia prevalence rises with family income (Sperduto, Seigel, Roberts, \& Rowland, 1983). A similar pattern has also been documented in studies in Singapore, Indonesia, and Australia (Saw et al., 2002; Wensor et al., 1999; Wong et al., 2000). Although the precise mechanism that produces these findings is not always clear (it is likely to be a combination of many factors), the positive relationship between income and reduced uncorrected visual acuity is a well-established empirical reality. As a consequence, considering the fact that incomes in Shaanxi are generally higher than those in Gansu (as discussed above), the gap, though quite large, appears to be consistent with findings in other parts of the world.

Likewise, the fact that the prevalence of reduced uncorrected visual acuity rises with grade level in our sample should not be surprising. Other studies outside of China (Dandona et al., 2002; Goh et al., 2005) and inside of China (Congdon et al., 2008; He et al., 2004, 2007) find positive age-reduced uncorrected visual acuity prevalence associations.

Despite there being relatively easy ways to overcome many effects of poor vision, only a small share of the students with reduced uncorrected visual acuity in our sample took any action to correct their problems (Table 3, row 2, column 1). Among the 4849 students that failed their visual acuity screening tests, only 856 self-reported that they had glasses. This means that only $4 \%$ of all grade four and grade five students-or $18 \%$ of students with reduced uncorrected visual acuity-self-reported wearing glasses. Moreover, on the day of the screening, our enumerators discovered (as part of their systematic enumeration) that only three percent of the students (or 605 out of 19,977) brought their glasses to school (Table 3, row 3, column 1). In other words, among those who failed the visual acuity screening and potentially needed glasses, only $12 \%$ actually brought a pair of glasses to school (605 out of 4849 ). It is for this reason that when one visits elementary schools in rural China, it is not uncommon to find that there are no students in an average-sized class of 40 that is wearing glasses. Similarly, it is difficult to find a class in which more than one or two students are wearing glasses.

Although the share of students with reduced uncorrected visual acuity owning glasses is low in both provinces, the rate in Shaanxi Province is slightly higher than that in Gansu (Table 3, row 2, columns 2 and 3). The proportion of students self-reporting that they 
Table 3

Results of visual acuity (VA) screening.

Data source: Authors' survey.

\begin{tabular}{|c|c|c|c|c|c|c|c|c|}
\hline & & $\begin{array}{l}\text { (1) } \\
\text { Full sample }\end{array}$ & $\begin{array}{l}(2) \\
\text { Gansu }\end{array}$ & $\begin{array}{l}(3) \\
\text { Shaanxi }\end{array}$ & $\begin{array}{l}(4) \\
\text { Grade } 4\end{array}$ & $\begin{array}{l}(5) \\
\text { Grade } 5\end{array}$ & $\begin{array}{l}\text { Difference } \\
(3)-(2)\end{array}$ & $\begin{array}{l}\text { Difference } \\
(5)-(4)\end{array}$ \\
\hline (1) & Proportion of failing screening & $\begin{array}{c}0.24 \\
(0.43)\end{array}$ & $\begin{array}{c}0.18 \\
(0.39)\end{array}$ & $\begin{array}{c}0.31 \\
(0.46)\end{array}$ & $\begin{array}{c}0.21 \\
(0.41)\end{array}$ & $\begin{array}{c}0.27 \\
(0.45)\end{array}$ & $\begin{array}{c}0.13^{\text {*** }} \\
{[0.0000]}\end{array}$ & $\begin{array}{c}0.06^{\text {**** }} \\
{[0.0000]}\end{array}$ \\
\hline$(2)$ & Proportion of already have glasses & $\begin{array}{c}0.04 \\
(0.20)\end{array}$ & $\begin{array}{c}0.03 \\
(0.17)\end{array}$ & $\begin{array}{c}0.06 \\
(0.23)\end{array}$ & $\begin{array}{c}0.03 \\
(0.18)\end{array}$ & $\begin{array}{c}0.05 \\
(0.22)\end{array}$ & $\begin{array}{l}0.03^{* * *} \\
{[0.0000]}\end{array}$ & $\begin{array}{l}0.02^{* * *} \\
{[0.0000]}\end{array}$ \\
\hline (3) & Proportion of brought glasses to schools & $\begin{array}{c}0.03 \\
(0.17)\end{array}$ & $\begin{array}{c}0.02 \\
(0.15)\end{array}$ & $\begin{array}{c}0.04 \\
(0.20)\end{array}$ & $\begin{array}{c}0.02 \\
(0.15)\end{array}$ & $\begin{array}{c}0.04 \\
(0.19)\end{array}$ & $\begin{array}{c}0.02^{* * *} \\
{[0.0000]}\end{array}$ & $\begin{array}{l}0.02^{* * * *} \\
{[0.0000]}\end{array}$ \\
\hline (4) & Proportion of poor vision & $\begin{array}{c}0.16 \\
(0.36)\end{array}$ & $\begin{array}{l}0.11 \\
0.20\end{array}$ & $\begin{array}{c}0.21 \\
(0.41)\end{array}$ & $\begin{array}{c}0.13 \\
(0.33)\end{array}$ & $\begin{array}{c}0.18 \\
(0.39)\end{array}$ & $\begin{array}{c}0.10^{* * *} \\
{[0.0000]}\end{array}$ & $\begin{array}{l}0.05^{* * * *} \\
{[0.0000]}\end{array}$ \\
\hline (5) & Proportion of mild poor vision & $\begin{array}{c}0.10 \\
(0.31)\end{array}$ & $\begin{array}{c}0.07 \\
(0.25)\end{array}$ & $\begin{array}{c}0.14 \\
(0.35)\end{array}$ & $\begin{array}{c}0.09 \\
(0.29)\end{array}$ & $\begin{array}{c}0.12 \\
(0.32)\end{array}$ & $\begin{array}{c}0.07^{* * *} \\
{[0.0000]}\end{array}$ & $\begin{array}{l}0.03^{* * *} \\
{[0.0000]}\end{array}$ \\
\hline (6) & Proportion of moderate poor vision & $\begin{array}{c}0.05 \\
(0.21)\end{array}$ & $\begin{array}{c}0.03 \\
(0.18)\end{array}$ & $\begin{array}{c}0.06 \\
(0.23)\end{array}$ & $\begin{array}{c}0.03 \\
(0.17)\end{array}$ & $\begin{array}{c}0.06 \\
(0.24)\end{array}$ & $\begin{array}{c}0.03^{* * *} \\
{[0.0000]}\end{array}$ & $\begin{array}{l}0.03^{* * * *} \\
{[0.0000]}\end{array}$ \\
\hline (7) & Proportion of severe poor vision & $\begin{array}{c}0.01 \\
(0.09)\end{array}$ & $\begin{array}{c}0.01 \\
(0.09)\end{array}$ & $\begin{array}{c}0.01 \\
(0.09)\end{array}$ & $\begin{array}{c}0.00 \\
(0.07)\end{array}$ & $\begin{array}{c}0.01 \\
(0.09)\end{array}$ & $\begin{array}{l}0.01 \\
{[0.1867]}\end{array}$ & $\begin{array}{l}0.01^{* *} \\
{[0.0192]}\end{array}$ \\
\hline & Number of schools screened & 253 & 120 & 133 & 253 & 253 & & \\
\hline & Number of students screened & 19,977 & 10,309 & 9668 & 9865 & 10,112 & & \\
\hline
\end{tabular}

Note:

a. S.D. is reported in parentheses.

b. p value of t-test is reported in brackets in the two columns to the right.

* Indicate significance at $10 \%$.

** Indicate significance at $5 \%$.

*** Indicate significance at $1 \%$.

have glasses is 3\% in Gansu Province and 6\% in Shaanxi Province. This means that, conditional on having vision problems, the share of students with glasses is roughly similar: $16 \%$ in Gansu and $18 \%$ in Shaanxi.

As noted above, we also report visual acuity results based on both eyes (using cutoffs set for the better eye). In our sample, there were 3129 students (16\% of the total population) with poor vision (that is, vision that is below our defined criterion of uncorrected visual acuity less than 6/12 in better eye-Table 3, row 4). In addition, the prevalence of mild, moderate and severe poor vision is $10 \%$ (2082 out of 19,977$), 5 \%(910 / 19,977)$ and $1 \%$ (137 out of 19,977-rows 5 to 7 ), respectively.

\section{Correlates of poor vision}

The high prevalence of poor vision found in our sample leads us to an important question: In poor, northwest China primary schools are certain types of children disproportionately at risk of having poor vision? Answering this question would allow health and/or education officials to tailor vision care policies or prevention/treatment programs in ways that might be able to serve the target population more efficiently (by targeting certain subpopulations first, and other subpopulations later, for example). The correlates to be analyzed include region (Shaanxi or Gansu), grade level (grade four or grade five), individual characteristics (gender, school boarding status), parental characteristics (level of parental education and migrant status) and family characteristics (household wealth).

To examine the correlates of poor vision, the paper presents findings of two empirical exercises. First, we present a series of descriptive correlates. We compare the characteristics listed above in the previous paragraph between those with normal vision and those with poor vision. Second, we employ an Ordinary Least Square (OLS) estimator to identify the correlates of poor vision using the following multivariate framework:

poor vision $_{i}=$ province $_{i}+$ grade $_{i}+$ individual characteristics $_{i}$

+ parental and family characteristics $s_{i}+\varepsilon_{i}$

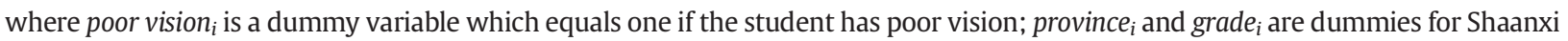

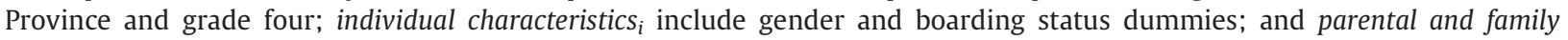
characteristics $_{i}$ include parental migrant status, educational background and family wealth; and $\varepsilon_{i}$ is clustered at the school level.

\subsection{Descriptive statistics}

The discussion on prevalence in the previous section highlights sharp differences in the share of individuals with poor vision by province and by grade level. According to our data, there are significantly more Shaanxi students in poor vision groups (64\%) relative to the normal vision group ( $45 \%, \mathrm{p}<0.01-$ Table 4 , row 1$)$. There are also significantly more grade five students in the poor vision group (60\%) relative to the normal vision group (49\%, $\mathrm{p}<0.01-$ row 4 ). These are consistent with the results in Table 3 (rows 1 and 2). 
Table 4

Descriptive statistics comparing students with normal vision and poor vision.

Data source: Authors' analysis of survey data.

\begin{tabular}{|c|c|c|c|c|c|}
\hline & & $\begin{array}{l}\text { (1) } \\
\text { Full sample }\end{array}$ & $\begin{array}{l}(2) \\
\text { Normal vision }\end{array}$ & $\begin{array}{l}(3) \\
\text { Poor vision }\end{array}$ & $\begin{array}{l}\text { Difference } \\
(3)-(2)\end{array}$ \\
\hline (1) & Home province of Shaanxi ( 1 = yes) & $\begin{array}{c}0.48 \\
(0.50)\end{array}$ & $\begin{array}{c}0.45 \\
(0.50)\end{array}$ & $\begin{array}{c}0.64 \\
(0.48)\end{array}$ & $\begin{array}{l}0.19^{* * *} \\
{[0.000]}\end{array}$ \\
\hline$(2)$ & Grade 4 ( $1=$ yes $)$ & $\begin{array}{c}0.49 \\
(0.50)\end{array}$ & $\begin{array}{c}0.51 \\
(0.50)\end{array}$ & $\begin{array}{c}0.40 \\
(0.49)\end{array}$ & $\begin{array}{l}-0.11^{* * * *} \\
{[0.000]}\end{array}$ \\
\hline \multicolumn{6}{|c|}{ Individual characteristics } \\
\hline (3) & Male $(1=$ yes $)$ & $\begin{array}{c}0.52 \\
(0.50)\end{array}$ & $\begin{array}{c}0.53 \\
(0.49)\end{array}$ & $\begin{array}{c}0.48 \\
(0.49)\end{array}$ & $\begin{array}{c}-0.05^{* * *} \\
{[0.000]}\end{array}$ \\
\hline$(4)$ & Boarding status ( 1 = boarding) & $\begin{array}{l}0.18 \\
(0.39)\end{array}$ & $\begin{array}{l}0.18 \\
(0.38)\end{array}$ & $\begin{array}{c}0.22 \\
(0.42)\end{array}$ & $\begin{array}{l}0.05^{* * *} \\
{[0.000]}\end{array}$ \\
\hline \multicolumn{6}{|c|}{ Parental and family characteristics } \\
\hline (5) & Parental migrant status ( 1 = both parents migrant) & $\begin{array}{c}0.12 \\
(0.33)\end{array}$ & $\begin{array}{c}0.13 \\
(0.34)\end{array}$ & $\begin{array}{c}0.10 \\
(0.30)\end{array}$ & $\begin{array}{c}-0.03^{* * *} \\
{[0.000]}\end{array}$ \\
\hline (6) & Father has education of 6 to 9 years $(1=$ yes $)$ & $\begin{array}{c}0.80 \\
(0.40)\end{array}$ & $\begin{array}{c}0.80 \\
(0.40)\end{array}$ & $\begin{array}{c}0.78 \\
(0.41)\end{array}$ & $\begin{array}{l}-0.02^{* *} \\
{[0.0373]}\end{array}$ \\
\hline (7) & Father has education of 12 years or more $(1=$ yes $)$ & $\begin{array}{l}0.13 \\
(0.34)\end{array}$ & $\begin{array}{c}0.13 \\
(0.33)\end{array}$ & $\begin{array}{c}0.15 \\
(0.36)\end{array}$ & $\begin{array}{l}0.02^{* * *} \\
{[0.005]}\end{array}$ \\
\hline$(8)$ & Mother has education of 6 to 9 years ( 1 = yes) & $\begin{array}{c}0.70 \\
(0.46)\end{array}$ & $\begin{array}{c}0.70 \\
(0.46)\end{array}$ & $\begin{array}{c}0.69 \\
(0.46)\end{array}$ & $\begin{array}{l}-0.01 \\
{[0.324]}\end{array}$ \\
\hline (9) & Mother has education of 12 years or more $(1=$ yes $)$ & $\begin{array}{c}0.09 \\
(0.28)\end{array}$ & $\begin{array}{c}0.08 \\
(0.28)\end{array}$ & $\begin{array}{c}0.10 \\
(0.31)\end{array}$ & $\begin{array}{l}0.02^{* * *} \\
{[0.000]}\end{array}$ \\
\hline$(10)$ & Medium wealth tercile ( 1 = yes) & $\begin{array}{c}0.28 \\
(0.45)\end{array}$ & $\begin{array}{c}0.29 \\
(0.45)\end{array}$ & $\begin{array}{c}0.25 \\
(0.44)\end{array}$ & $\begin{array}{c}-0.03^{* * *} \\
{[0.001]}\end{array}$ \\
\hline$(11)$ & Top wealth tercile $(1=$ yes $)$ & $\begin{array}{c}0.36 \\
(0.48)\end{array}$ & $\begin{array}{c}0.34 \\
(0.47)\end{array}$ & $\begin{array}{c}0.46 \\
(0.50)\end{array}$ & $\begin{array}{c}0.12^{* * *} \\
{[0.000]}\end{array}$ \\
\hline & Number of schools screened & 253 & 253 & 253 & \\
\hline & Number of students screened & 19,977 & 16,848 & 3129 & \\
\hline
\end{tabular}

Note:

a. S.D. is reported in parentheses in columns 1 to 3 .

b. In column 4, p value is reported in brackets. Standard errors account for clustering at the school level.

* Indicate significance at $10 \%$.

** Indicate significance at $5 \%$.

*** Indicate significance at $1 \%$.

Our descriptive statistics also show that girls seem to be more vulnerable to poor vision than boys (Table 4, row 5 ). In the poor vision group, $52 \%$ are girls, while in the normal vision group, only $47 \%$ are girls. The difference is statistically significant ( $\mathrm{p}<0.01$ ). Our finding of a higher prevalence of poor vision among school-aged girls is consistent with findings from studies in urban southeast China, rural India, and Malaysia (Dandona et al., 2002; Goh et al., 2005; He et al., 2004).

Our data also demonstrate that poor vision among children is positively and significantly correlated with school boarding status, parental educational background and family wealth. Specifically, in our sample students with poor vision are more likely to board at school (22\%) than students with normal vision (18\%-Table 4, row 5). Students with poor vision are slightly more likely to have parents with better education compared with students with normal vision. Fifteen percent of fathers of students with poor vision have 12 or more years of education, while the proportion of fathers with the same level of education in the group of normal vision students is 13\% (row 7). And the proportion of mothers with 12 or more years of education is also slightly higher in the group of poor vision students (10\%) compared to that in the group of normal vision students ( $8 \%-$ row 9 ). Finally, the data show that $46 \%$ of students with poor vision live in the richest tercile of families, ${ }^{9}$ while only $34 \%$ of students with normal vision do (row 15 ). This finding is consistent with that of many others studies that draw a positive correlation between myopia and various indicators of socio-economic status (Saw et al., 2002; Wensor et al., 1999; Wong et al., 2000). All differences reported above are statistically significant ( $\mathrm{p}<0.01-$ Table 4 , far right column).

In contrast, we find that poor vision among children is negatively and significantly correlated with parental migration status. According to the descriptive statistics, students with poor vision appear to be less likely to have both parents out migrating for work when compared to students with parents that live at home (Table 4, row 8). Specifically, 10\% of children with poor vision were from families in which both parents out-migrated; compared to $13 \%$ among children with normal vision $(\mathrm{p}<0.01)$.

\footnotetext{
9 The wealth measurement in our data is divided into 3 terciles: Low, Medium and High. The Low tercile includes the poorest families; the High tercile includes the richest families. Because the wealth measurement is not a continuous variable, the data is not evenly broken down into three groups. Instead, Low, Medium and High wealth tercile represents $36 \%, 28 \%$, and $36 \%$ of our sample, respectively.
} 
Table 5

Results from Ordinary Least Squares and Logit estimates of the correlates of poor vision correlates. Data source: Authors' analysis of survey data.

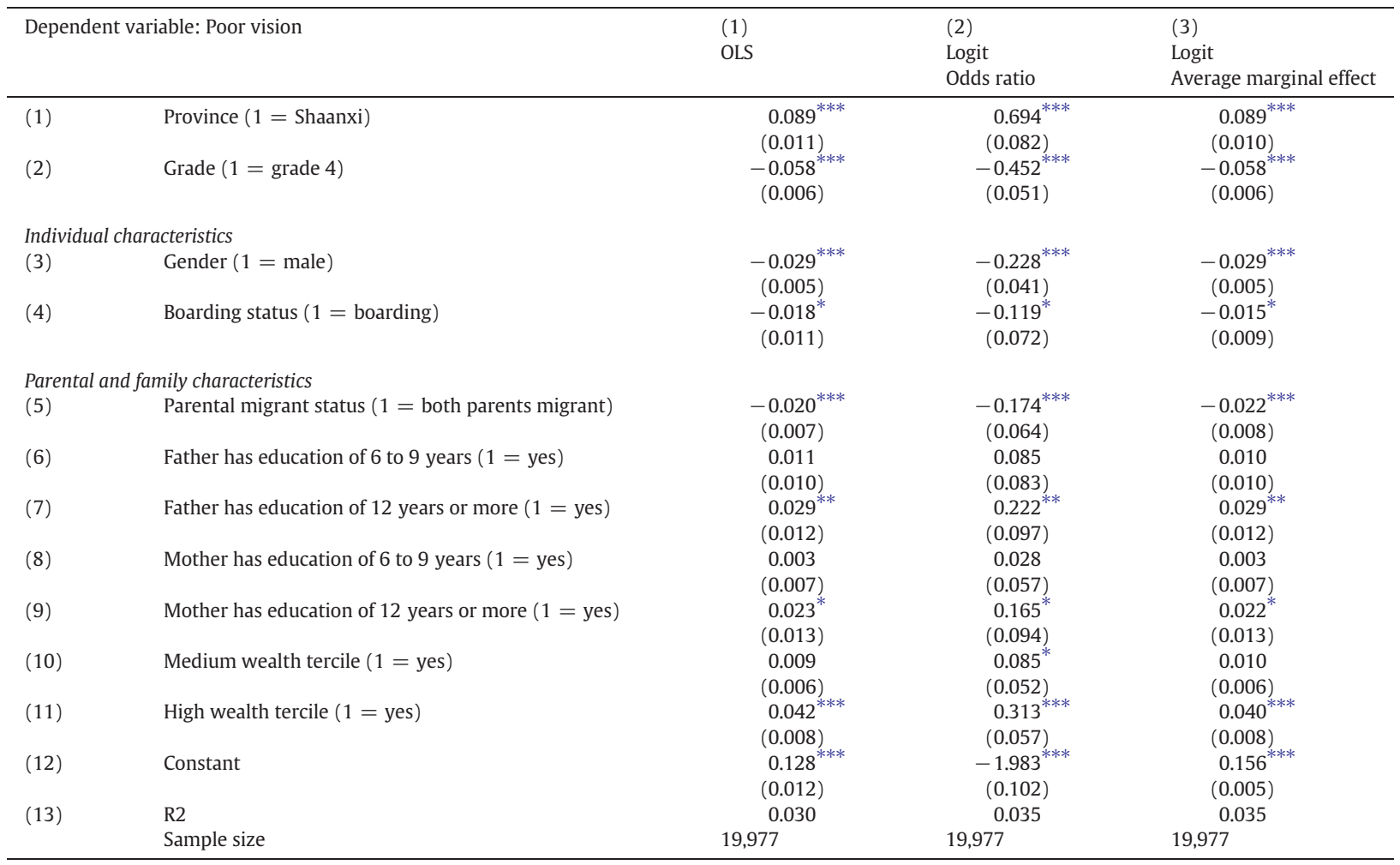

Note:

a. Standard errors clustered at the school level are reported in parentheses.

b. The first dummy (omitted) in father/mother education represents father/mother illiteracy.

c. The first wealth tercile (omitted) represents households with the Low wealth tercile.

* Indicate significance at $10 \%$.

** Indicate significance at $5 \%$.

*** Indicate significance at $1 \%$

\subsection{Multivariate analysis}

The results of the multivariate analysis are mostly consistent with the descriptive statistics. We include estimates of both OLS and Logit (in columns 1 and 2 of Table 5). In order to compare the results, we include a third column (Table 5, column 3), in which we report the marginal effects associated with the Logit estimates. As can be seen by comparing the results in columns 1 and 3 of Table 5, the estimates from both OLS and the Logit are nearly the same. The strongest of the correlates are for province and grade effects, which is consistent with the findings described in the sections above. The multivariate analysis demonstrates that, ceteris paribus, there are strong correlations by province. On average, students in Shaanxi Province are nine percentage points more likely to have poor vision relative to students in Gansu Province, given that other characteristics are equal (Table 5, row 1). There are also strong correlations found between vision by grade level. Students in grade four are 6 percentage points less likely to have poor vision relative to students in grade five (row 2).

The multivariate results also show that poor vision is negatively and significantly correlated with gender and parental migration status while significantly and positively correlated with parental educational background and family wealth (these finding are all consistent with the descriptive results). For example, in the case of gender, the statistically significant coefficient for gender ( -0.03 , $\mathrm{p}<0.01$ ) suggests that girls are on average 3 percentage points more likely to have poor vision relative to boys, when controlling for other conditions (Table 5, row 3 ). The statistically significant coefficient for the parental migration status variable ( -0.02 , $\mathrm{p}<0.01$ ) means that children of both parents that are migrants are on average two percent less likely to have poor vision compared to children of parents that live and work at home (row 5). Also, as in the case of the descriptive statistics, there are positive and significant correlations between poor vision and parental educational background (rows 8 and 10) and family wealth (rows 11 and 12). In other words, these findings suggest that children of higher-educated parents and wealthier families are more likely to have poor vision relative to those of less-educated parents and poorer families. 
There is only one minor difference between the results of the multivariate analysis and the descriptive statistics. Instead of finding a positive and significant correlation between the poor vision and children's boarding status-as we did in the descriptive statistics (Table 4, row 4), a negative correlation between them was found in the multivariate analysis (Table 5, row 4). There is clearly some sort of correlation among the correlates themselves that is disguising the true association between vision and boarding status when univariate descriptive statistics are used.

\subsection{Magnitudes of differences}

Although we did find a large number of statistically significant correlations between poor vision and student characteristics, with the exception of the by province and by grade correlations, the magnitudes of the differences in the correlates are generally small. On average, there is at most only a three percentage point difference between those with normal vision and those with poor vision when examining individual and parental characteristics (Table 4, rows 3 to 9). In the multivariate analysis, the coefficients for many of the correlates are less than 0.03 (Table 5, rows 3 to 9). This suggests that most correlates only account for a 3 percentage point difference in the likelihood of a child having poor vision. Even in the case of family wealth, the coefficient for the high wealth tercile (the richest one third of the sample individuals) is only 0.04 , meaning that if a student lives in a well-off family, he or she is only $4 \%$ more likely to have poor vision when compared to an individual from a poor family (all other things held constant).

What can we conclude from the small magnitudes of the correlations? Importantly (with the exception of students that live in different provinces or are in different grades), the share of normal and poor vision is nearly the same when comparing boys and girls. The nature of vision is also almost the same for other characteristics: for those that live at home and those that board at school; for those that have parents at home; for those that have parents that out-migrate; and for those that have parents that have higher levels of education. Even when comparing better off students with poor students, the rates of poor vision among children are not very different. This may suggest that the behavior and environmental factors we measured (gender; boarding status; nature of parents' occupation; the level of parents' education; or the wealth of the family) do not play a major role in modulating risk for poor vision. At this age (grade four and grade five), the underlying risk of poor vision is sufficiently high and all children are susceptible to poor vision. In terms of policy implications or vision care design, such results can be interpreted as suggesting that at this age (in primary schools in poor rural areas) all students require vision care, not just a subset of students.

\section{Poor vision and academic performance}

The high prevalence of poor vision and the fact that it occurs in our sample irrespective of individual and parental/family characteristics (with the exceptions of province and grade) lead us to consider a set of important but understudied questions: is there any adverse impact of poor vision on children? More precisely, in the context of schools, is visual acuity correlated with academic performance? When a student has poor vision, do they perform poorly in school? If so, to what extent? The answers to these questions not only enable us to better understand the impact of vision on children's school performance, but also provide a more complete accounting of how the health-education dynamic affects the development of human capital when children are young.

\subsection{Estimation strategy}

To estimate the correlation between poor vision and children's academic performance, we employ both nonparametric and parametric methods. We begin with a nonparametric approach to illustrate the relationship between academic performance (defined by each student's score on the standardized math test that was administered during the survey-or the Standardized Math Score) and the linear visual acuity measurement (LogMAR). The relationship can be graphically summarized by a Locally Weighted Scatterplot Smoothing (Lowess) plot. One advantage of using the Lowess approach is that it can provide a quick summary of the relationship between two variables. Lowess results are nonparametric: one does not need to specify a function that specifies the relationship between the two variables. The simplicity of the Lowess approach, however, comes at the expense of controlling for other factors in examining the relationship between vision and academic performance.

In order to overcome this shortcoming in the Lowess approach, we also use a parametric regression approach. Specifically, Ordinary Least Squares (OLS) regressions are used to estimate the relationship between vision and academic performance. The basic model is:

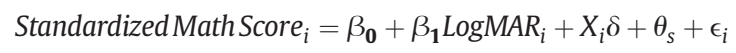

where $X_{i}$ controls for the variables: grade level, gender, boarding status, parental migration status, parental educational background, and family wealth; $\theta_{s}$ represents a set of school-level dummy variables that controls for all school fixed effects; and $\epsilon_{i}$ is clustered at the school level.

Although the linear regression model specified in Eq. (2) measures the average correlation of poor vision against academic performance, we need an alternative set of specifications to measure heterogeneous effects. We need this because we are interested in knowing if the school performance of those with severe poor vision may be worse than the performance of their classmates that only have moderate or mild poor vision. For this reason, we stratify the severity of poor vision into three categories using the cutoffs 


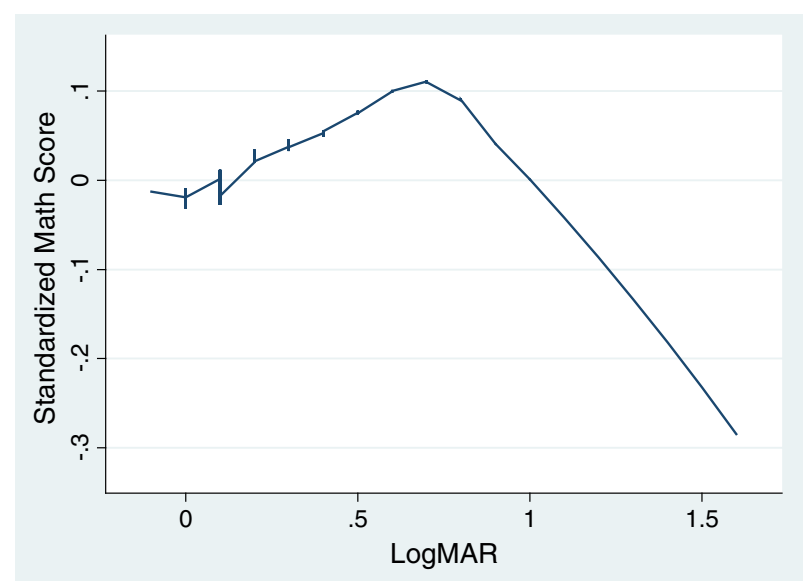

Fig. 2. Lowess plot of the relationship between LogMAR and Standardized Math Scores. Note: LogMAR is defined as Log10 (1/VA). Therefore, the larger the LogMAR, the smaller one's VA and the poorer one's vision is. In this analysis we use the results based on the better eye (the eye with the least poor vision) of each student. Data source: Authors' data.

defined in the Prevalence of poor vision section: mild poor vision, moderate poor vision, and severe poor vision, modifying our basic model as following:

Standardized Math Score ${ }_{i}=\beta_{0}+\beta_{11}$ mild poor vision ${ }_{i}$

$+\beta_{12}$ moderate poor vision $_{i}+\beta_{13}$ severe poor vision $_{i}+X_{i} \delta+\theta_{s}+\varepsilon_{i}$.

\subsection{Results}

The nonparametric Lowess plot demonstrates a generally negative relationship between vision and academic performancealthough there are differences as vision proceeds from normal to severe poor (Fig. 2). As one starts to move from left to right across the graph, the standardized test scores first rise gradually. Importantly, however, when LogMAR vision reaches approximately 0.7 (equivalent to visual acuity of 6/30, roughly equivalent to moderate poor vision), the standardized test scores of students start to fall. After that point, the Lowess plot demonstrates that test scores fall monotonically and dramatically as the vision of students worsens. In other words, our data suggest that a student's test score decreases as his/her vision deteriorates, especially in the case of those that have moderate and severe vision problems.

Before examining the results of the multivariate regression analysis of the association between vision and academic performance, we first assess how the model (from Eq. (2), specifically) is performing. The coefficients on the control variables in the OLS regression equations suggest that the data were of high quality and that the regression performed well (Table 6, rows 4 to 14 ). For example, we found significant, negative coefficients for parental migration status $(-0.04)$ in all three models, with different specifications of poor vision-columns 1 and 2. This finding suggests that children who are living with other caregivers while both parents work and live away from home as migrants have standardized test scores that are 0.04 standard deviations lower relative to those students with parents that live and work at home (row 8). The negative relationship between migration status of parents and student academic performance is consistent with other findings in the literature (McKenzie \& Rapoport, 2006). In addition, the results also show (as is found in the literature-Brown \& Park, 2002; Chen et al., 2007) that standardized test scores rise as parental education (rows 9 to 12 ) and family wealth (rows 13 and 14) rise. The negative association of the school boarding variable with test performance in this data set (row 7) is consistent with the results of Mo et al. (2012) and Chen et al. (2014).

According to model 1, holding other variables constant, visual acuity is negatively associated with test performance (Table 6, row 1 and column 1 ). The coefficient for the LogMAR variable $(-0.082)$ suggests that, on average, one line of loss in visual acuity (measured using the ETDRS chart) is associated with nearly a 0.1 standard deviation loss in the math test score $(\mathrm{p}<0.01)$.

The results from the second model (Table 6, column 2 ) also suggest that the association between vision and test scores evolves as a student's vision worsens. In fact, in the case of those students with only mild poor vision problems, test scores are actually higher (row 4). This is not unexpected: based on available epidemiological evidence students who are doing more homework and reading more might be expected to have poorer vision and higher grades (Saw et al., 2000). However, when students have moderate poor vision, their scores tend to be lower relative to those with normal vision (the coefficient of moderate poor vision is -0.04 , though not statistically significant-row 3 ). This trend is consistent with the finding in Lowess plot. What is more, when students have severe poor vision, the coefficient $(-0.28, \mathrm{p}<0.01)$ suggests that standardized test scores are significantly lower than for students with normal vision (row 4). In the field of education, a difference in test scores of 0.2 standard deviations is typically thought to be relatively large (equivalent to additional learning that might occur over a period of 6 months to a full school year, Kremer, 


\section{Table 6}

OLS estimation of correlation between vision and academic performance.

Data source: Authors' analysis of survey data.

\begin{tabular}{|c|c|c|c|}
\hline \multicolumn{2}{|c|}{ Dependent variable: Standardized Math Score } & \multirow{2}{*}{$\begin{array}{l}(1) \\
\\
\quad-0.081^{* * *} \\
\quad(0.030)\end{array}$} & \multirow[t]{2}{*}{$(2)$} \\
\hline $\begin{array}{l}\text { Vision } \\
(1)\end{array}$ & LogMAR & & \\
\hline$(2)$ & Severe poor $(1=$ yes $)$ & & $\begin{array}{l}-0.277^{* * *} \\
(0.094)\end{array}$ \\
\hline (3) & Moderate poor $(1=$ yes $)$ & & $\begin{array}{r}-0.043 \\
(0.030)\end{array}$ \\
\hline (4) & Mild poor $(1=$ yes $)$ & & $\begin{array}{l}0.052^{* *} \\
(0.024)\end{array}$ \\
\hline $\begin{array}{l}\text { Individ } \\
\text { (5) }\end{array}$ & Grade $(1=$ grade 4$)$ & $\begin{array}{c}0.004 \\
(0.027)\end{array}$ & $\begin{array}{c}0.002 \\
(0.027)\end{array}$ \\
\hline (6) & Gender ( 1 = male $)$ & $\begin{array}{r}-0.011 \\
(0.014)\end{array}$ & $\begin{array}{r}-0.008 \\
(0.013)\end{array}$ \\
\hline (7) & Boarding status ( $1=$ boarding) & $\begin{array}{r}-0.021 \\
(0.027)\end{array}$ & $\begin{array}{r}-0.021 \\
(0.027)\end{array}$ \\
\hline \multicolumn{4}{|c|}{ Parental and family characteristics } \\
\hline$(8)$ & Parental migrant status ( $1=$ both parents migrant) & $\begin{array}{c}-0.042^{* *} \\
(0.021)\end{array}$ & $\begin{array}{r}-0.041^{*} \\
(0.021)\end{array}$ \\
\hline (9) & Father has education of 6 to 9 years ( $1=$ yes) & $\begin{array}{l}0.215^{* * *} \\
(0.030)\end{array}$ & $\begin{array}{l}0.215^{* * *} \\
(0.030)\end{array}$ \\
\hline$(10)$ & Father has education of 12 years or more ( 1 = yes) & $\begin{array}{l}0.340^{* * *} \\
(0.039)\end{array}$ & $\begin{array}{l}0.340^{* * *} \\
(0.039)\end{array}$ \\
\hline (11) & Mother has education of 6 to 9 years $(1=$ yes $)$ & $\begin{array}{l}0.082^{* * *} \\
(0.018)\end{array}$ & $\begin{array}{l}0.082^{* * *} \\
(0.018)\end{array}$ \\
\hline$(12)$ & Mother has education of 12 years or more $(1=$ yes $)$ & $\begin{array}{l}0.173^{* * * *} \\
(0.031)\end{array}$ & $\begin{array}{l}0.172^{* * *} \\
(0.031)\end{array}$ \\
\hline$(13)$ & Medium wealth tercile ( 1 = yes) & $\begin{array}{l}0.070^{* * *} \\
(0.017)\end{array}$ & $\begin{array}{l}0.070^{* * *} \\
(0.017)\end{array}$ \\
\hline$(14)$ & High wealth tercile ( 1 = yes) & $\begin{array}{l}0.092^{* * *} \\
(0.019)\end{array}$ & $\begin{array}{l}0.090^{* * *} \\
(0.019)\end{array}$ \\
\hline$(15)$ & Constant & $\begin{array}{c}-0.524^{* * *} \\
(0.041)\end{array}$ & $\begin{array}{c}-0.542^{* * *} \\
(0.041)\end{array}$ \\
\hline$(16)$ & $\mathrm{R} 2$ & 0.171 & 0.172 \\
\hline & Sample size & 19,977 & 19,977 \\
\hline
\end{tabular}

Note:

a. Standard errors clustered at the school level are reported in parentheses.

b. The first dummy (omitted) in father/mother education represents father/mother illiteracy.

c. The first wealth tercile (omitted) represents households with the Low wealth tercile.

* Indicate significance at $10 \%$

** Indicate significance at $5 \%$.

*** Indicate significance at $1 \%$.

2003; Levitt, List, Neckermann, \& Sadoff, 2012). Hence, the findings are clear: as a student's vision worsens, there is a steep drop in the academic performance.

\section{Poor vision and mental health}

Another potential adverse impact of poor vision that we studied affects children's mental health. There is literature documenting the negative effects of poor vision on mental health, as well as the psychological benefits of the correction of poor vision (by wearing glasses; see Muñoz et al., 2002; Coleman, Yu, Keeler, \& Mangione, 2006). However, existing research focuses on adults and especially the elderly. Taking advantage of our large sample size in China's rural areas, this paper will shed light on the relationship between children's poor vision and mental health.

We applied multivariate analysis to study the correlation between children's poor vision and mental health using the same models described in the section above. The results suggest that poor vision is positively and significantly associated with worse mental health (measured by higher anxiety level-Table 7). When controlling for other variables, we found that on average, one line of loss in visual acuity (measured using the ETDRS chart) is associated with a 0.25 standard deviation increase in standardized MHT score ( $\mathrm{p}<0.01-$ row 1 , column 1 ).

More importantly, we found that the magnitude of the correlation becomes larger when one's vision deteriorates from mild poor vision to severe poor vision (rows 2 to 4 , column 1). Compared to students with normal vision, the standardized MHT scores increases by 0.08 standard deviation among the students with mild vision; by 0.16 standard deviation among students with moderate poor vision and by 0.32 standard deviation among students with severe poor vision. According to Cohen (1988), our finding is between 
Table 7

OLS estimation of correlation between vision and mental health.

Data source: Authors' survey.

Dependent variable:

Standardized MHT score

\section{Vision}

(1)

(2)

(3)

(4)

Individual characteristics

(5)

(6)

Parental and family characteristics

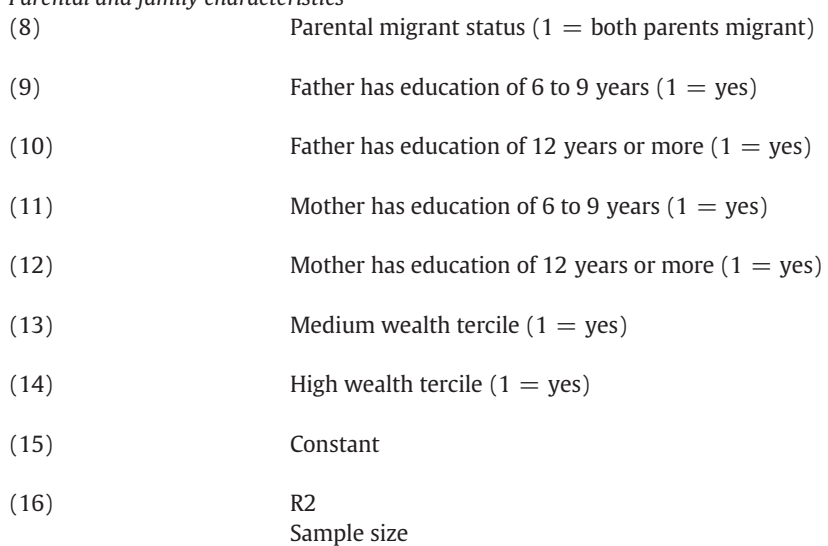

Severe poor $(1=$ yes $)$
(1)

(2)

$$
\begin{aligned}
& 0.250^{\text {**** }} \\
& (0.036)
\end{aligned}
$$

0.006
$(0.024)$
$-0.118^{* * *}$
$(0.016)$
$0.102^{* * *}$
$(0.025)$

0.005

(0.024)

$-0.122^{* *}$

(0.016)

$0.102^{* * * *}$

(0.025)

$$
\begin{gathered}
0.078^{\text {*** }} \\
(0.022) \\
-0.063^{* *} \\
(0.031) \\
-0.105^{* * *} \\
(0.034) \\
-0.079^{* * *} \\
(0.018) \\
-0.134^{\text {*** }} \\
(0.032) \\
-0.027 \\
(0.019) \\
-0.018 \\
(0.021) \\
0.172^{* * *} \\
(0.043) \\
0.074
\end{gathered}
$$$$
0.077^{* * *}
$$$$
(0.022)
$$$$
{ }^{(0.022)}{ }^{* *}
$$$$
\text { (0.031) }
$$$$
-0.105^{* * *}
$$$$
\text { (0.034) }
$$$$
-0.078^{* *}
$$$$
\text { (0.018) }
$$$$
-0.134^{* * *}
$$$$
(0.032)
$$$$
-0.026
$$$$
\text { (0.019) }
$$$$
-0.016
$$$$
\text { (0.021) }
$$$$
0.192^{* * *}
$$$$
\text { (0.043) }
$$

0.073

\section{Note:}

a. Standard errors clustered at the school level are reported in parentheses.

b. The first dummy (omitted) in father/mother education represents father/mother illiteracy.

c. The first wealth tercile (omitted) represents households with the Low wealth tercile.

* Indicate significance at $10 \%$.

** Indicate significance at $5 \%$.

*** Indicate significance at $1 \%$.

a small ( 0.20 standard deviation) and a medium ( 0.50 standard deviation) effect size. The finding is also comparable to that of other studies done in China (e.g., the intervention of multiple micronutrient supplementation for 36 weeks reduced MHT score by 0.30 standard deviations, Zhang et al., 2013).

\section{Conclusion}

In this paper we document the high prevalence of reduced uncorrected visual acuity and poor vision using the results from visual acuity screening among 19,977 grade four and grade five students in 253 primary schools in poor, rural parts of Gansu Province and Shaanxi Province in northwest China. According to our data, $24 \%$ of the sample children have reduced uncorrected visual acuity. Although China is among the countries with the highest reported levels of reduced visual acuity in the world, the high rates of prevalence found in Gansu and Shaanxi are somewhat surprising. We also found a higher prevalence of reduced uncorrected visual acuity in less poor areas (31\% in moderately poor Shaanxi versus 18\% in Gansu, China's poorest province) and among older children ( $27 \%$ in grade five versus $21 \%$ in grade four). This finding is consistent with previous studies inside (Congdon et al., 2008; He et al., 2004, 2007) and outside of China (Dandona et al., 2002; Goh et al., 2005; Saw et al., 2002; Wensor et al., 1999; Wong et al., 2000). We also found a prevalence rate of $16 \%$ for children with poor visual acuity in the better eye.

Given the high prevalence of poor vision, the rates of eyeglasses used appear to be quite low. Only $4 \%$ of our sample self-reported having eyeglasses. Only 3\% actually brought their eyeglasses to school. These findings raise a number of important concerns regarding 
vision care in rural areas. It is possible that children (or their parents or teachers) either do not know that they have a vision problem, do not know what to do about it, and do not believe it is an important consideration or some combination of these and other factors.

In view of this high observed prevalence of poor vision employed both descriptive statistics and multivariate analysis to identify potential risk factors (gender, boarding status, parental migration status, parental educational background and family wealth). We found statistically significant correlations between poor vision and province, grade level, gender, boarding status, parental migration status, parental educational background and family wealth. However, the magnitudes of most of the correlates were relatively small (with the exception of province and grade level). The high prevalence of poor vision across strata of children irrespective of these social demographic factors strongly suggests that vision screening and care must be made available to children across all segments of society in this setting.

We demonstrated the potential impact of poor vision on children's academic performance: poor vision is negatively and significantly correlated with academic performance. Specifically, in our regression analysis we found that, on average, one line of loss in visual acuity (measured in ETDRS chart) is associated with a nearly 0.1 standard deviation loss in math score ( $p<0.01$ ). This impact is most prominent among students with severe poor vision, who had test scores 0.28 standard deviations ( $\mathrm{p}<0.01$ ) lower than those of students with normal vision, equivalent to the additional learning that might occur over six months to a full school year.

Finally, we found that poor vision is positively and significantly associated with worse mental health (measured by higher anxiety level using MHT test): on average, one line of loss in visual acuity (measured in ETDRS chart) is associated with a 0.25 standard deviation increase in standardized MHT score $(\mathrm{p}<0.01)$. More importantly, the magnitude of the correlation becomes larger when one's vision deteriorates from mild poor vision to severe poor vision. Students with sever poor vision had standardized MHT score 0.32 standard deviations higher than students with normal vision, which is between a small ( 0.20 standard deviation) and a medium (0.50 standard deviation) effect size.

Twenty-four percent of children in our sample suffer from poor vision. Recent research shows that this condition has a significant and negative impact on their educational performance (Ma et al., in press), in addition to other outcomes noted in this paper. We can therefore conclude that these children are suffering from a highly treatable burden of vision disability. Other recent research has shown that regular wearing of glasses can slow the progression of myopia for a myopic child (Congdon et al., in press). Given these considerations, it is incumbent upon healthcare providers and/or social planners to get all $24 \%$ of these children into a pair of properly prescribed eyeglasses. That being said, significant barriers, both on the supply and demand sides, may preclude the universal provision of proper vision care for these children. Nevertheless, it appears that for children with moderate to severe myopia the cost of noncorrection in terms of decreased quality of life and productivity so far outweigh those of correction that social planners could reasonably consider a plan to subsidize care for at least this most vulnerable segment of children. Yi, Ma, Zenf, Shi, and Rozelle (2014) further shows that with a subsidy a majority of children that could potentially benefit from correction will seek care. It is possible that the costs of subsidizing care will be recouped in short order as children's school performance and quality of life rise after receiving correction.

Insofar as the delivery of care, perhaps the ideal solution to the problem is to have vision screening incorporated into regular annual health checks that are supposed to occur in all rural schools. However, evidence shows that these checks rarely occur and even when they do include vision screening it is not done well (Congdon et al., 2008). The reason for the irregularity of health checks may be that the nearest clinicians are commonly based in the county seat, which can be very distant, and have little incentive to undertake costly travel to local schools to provide health checks. Ensuring that high quality health checks occur regularly has many obvious benefits but may require significant investment on the part of provincial or even national level authorities. In the absence of such investments (there are none, currently), having teachers take on some of the burden seems a reasonable step at least insofar as vision screening is concerned.

Indeed, evidence indicates that such a modest investment in teachers can be effectual. For example, Sharma et al. (2008) has shown that after a brief training session from a clinician, teachers can successfully and accurately take on the burden of screening children for vision problems in their classes or schools, and refer non-passing children to specialists in the county seat for further examination. Sharing the screening burden with teachers based locally nearly eliminates the need for clinicians to travel to distant schools to provide this first level of care. Teacher-led annual screenings could therefore be mandated at minimal cost to the school.

Costs associated with such a mandate seem to be minimal. Training one teacher from each school in visual acuity screening techniques at the local county hospital would require each school to pay to and fro transport to the county seat (perhaps 50 RMB, or US\$8). Screening equipment can be obtained for about 100 RMB (US\$16). The hospital would need to provide two training staff for half of a day. We feel these are minimal and acceptable costs for schools and hospitals to take on, especially if the hospitals, many of which provide optician services, are able to sell even subsidized glasses to children found to need them.

Given that most of the vision problems we studied in this paper are readily correctable, we can conclude that accurate in-school vision screening may be feasible, cost effective, and capable of delivering significant productivity and quality of life benefits to rural Chinese children.

\section{Acknowledgement}

We are grateful for the financial and technical support from OneSight Research Foundation, Luxottica-China, Essilor and CLSA. We also acknowledge the funding from the National Natural Science Foundation of China (NSFC grant number 71103171) and Bingwei Excellent Young Scientist Program (grant number 2013RC204) supported by the Institute of Geographical Sciences and Natural Resources Research of Chinese Academy of Sciences. The funding sources did not have a role in the design or conduct of the study; 
collection, management, analysis, or interpretation of the data; preparation, review, or approval of the manuscript; or decision to submit the manuscript for publication.

\section{References}

American Foundation for the Blind (2002, January). Living with low vision. Retrieved from http://www.afb.org/section.aspx?SectionID=26\&TopicID=144

Bailey, I.L., \& Lovie, J. (1976). New design principles for visual acuity letter charts. American Journal of Optometry and Physiological Optics, 53(11), 740.

Bourne, R.R., Dineen, B.P., Huq, D.M.N., Ali, S.M., \& Johnson, G.J. (2004). Correction of refractive error in the adult population of Bangladesh: Meeting the unmet need. Investigative Ophthalmology E' Visual Science, 45(2), 410-417.

Brown, P.H., \& Park, A. (2002). Education and poverty in rural China. Economics of Education Review, 21(6), 523-541.

Camparini, M., Cassinari, P., Ferrigno, L., \& Macaluso, C. (2001). ETDRS-fast: Implementing psychophysical adaptive methods to standardized visual acuity measurement with ETDRS charts. Investigative Ophthalmology E' Visual Science, 42(6), 1226-1231.

Chadha, R.K., \& Subramanian, A. (2011). The effect of visual impairment on quality of life of children aged 3-16 years. British Journal of Ophthalmology, 95(5), 642-645.

Chen, X., Huang, Q., Rozelle, S., \& Zhang, L. (2007). Migration, money and mother: The effect of migration on children's educational performance in rural China. Paper presented at the 2007 Annual Meeting, July 29-August 1, 2007, Portland, Oregon TN.

Chen, X., Yi, H., Zhang, L., Di, M., Chu, J., \& Rozelle, S. (2014). Do poor students benefit from China's merger program? Transfer path and educational performance. Asia Pacific Journal of Education, 34(1), 15-35.

China National Bureau of Statistics (2012). China statistical yearbook. Beijing, China: China Statistics Press.

Cohen, J. (1988). Statistical power analysis for the behavioral sciences. Hillsdale, NJ: Lawrence Erlbaum Associates, Inc.

Coleman, A.L., Yu, F., Keeler, E., \& Mangione, C.M. (2006). Treatment of uncorrected refractive error improves vision-Specific quality of life. Journal of the American Geriatrics Society, 54(6), 883-890.

Congdon, N., Ma, X., Yi, H., Zhou, Z., Pang, X., Meltzer, M., et al. (2015s). Safety of spectacle wear for the vision of myopic children: The “Seeing is Learning" clusterrandomized controlled trial. (in press).

Congdon, N., Wang, Y., Song, Y., Choi, K., Zhang, M., Zhou, Z., et al. (2008). Visual disability, visual function, and myopia among rural Chinese secondary school children: The Xichang Pediatric Refractive Error Study (X-PRES)-Report 1. Investigative Ophthalmology \& Visual Science, 49(7), $2888-2894$.

Cumberland, P.M., Peckham, C.S., \& Rahi, J.S. (2007). Inferring myopia over the lifecourse from uncorrected distance visual acuity in childhood. British Journal of Ophthalmology, 91(2), 151-153.

Dandona, R., Dandona, L., Srinivas, M., Sahare, P., Narsaiah, S., Muñoz, S.R., et al. (2002). Refractive error in children in a rural population in India. Investigative Ophthalmology E' Visual Science, 43(3), 615-622.

Esteso, P., Castanon, A., Toledo, S., Rito, M.A.P., Ervin, A., Wojciechowski, R., et al. (2007). Correction of moderate myopia is associated with improvement in selfreported visual functioning among Mexican school-aged children. Investigative Ophthalmology E Visual Science, 48(11), 4949-4954.

Fotouhi, A., Hashemi, H., Raissi, B., \& Mohammad, K. (2006). Uncorrected refractive errors and spectacle utilization rate in Tehran: The unmet need. British Journal of Ophthalmology, 90(5), 534-537.

Glewee, P., Park, A., \& Zhao, M. (2011). Visualizing development: Eyeglasses and academic performance in rural primary schools in China. Working paper.

Goh, P. -P., Abqariyah, Y., Pokharel, G.P., \& Ellwein, L.B. (2005). Refractive error and visual impairment in school-age children in Gombak District, Malaysia. Ophthalmology, 112(4), 678-685.

Grosvenor, T. (2007). Primary care optometry. St. Louis, Missouri: Elsevier, 174-175.

He, M., Huang, W., Zheng, Y., Huang, L., \& Ellwein, L.B. (2007). Refractive error and visual impairment in school children in rural southern China. Ophthalmology, 114(2), 374-382.

He, M., Zeng, J., Liu, Y., Xu, J., Pokharel, G.P., \& Ellwein, L.B. (2004). Refractive error and visual impairment in urban children in southern China. Investigative Ophthalmology \& Visual Science, 45(3), 793-799.

Kremer, M. (2003). Randomized evaluations of educational programs in developing countries: Some lessons. The American Economic Review, 93(2), 102-106.

Levitt, S.D., List, J.A., Neckermann, S., \& Sadoff, S. (2012). The behavioralist goes to school: Leveraging behavioral economics to improve educational performance. National Bureau of Economic Research working paper.

Li, L., Lam, J., Lu, Y., Ye, Y., Lam, D.S., Gao, Y., et al. (2010). Attitudes of students, parents, and teachers toward glasses use in rural China. Archives of Ophthalmology, $128(6), 759$.

Liu, X., Li, L., Yuan, J., \& Yu, C. (2012). Comparative study of personality characteristics and mental health between senior high school students with high myopia and low-to-moderate myopia. Recent Advances in Ophthalmology, 32(10), 963-965.

Luo, H., Gazzard, G., Liang, Y., Shankar, A., Tan, D.T., \& Saw, S. (2006). Defining myopia using refractive error and uncorrected logMAR visual acuity >0.3 from 1334 Singapore school children ages 7-9 years. British Journal of Ophthalmology, 90(3), 362-366.

Ma, X., Zhou, Z., Yi, H., Pang, X., Shi, Y., Chen, Q., et al. (2015s). Providing free glasses improves children's educational outcomes: The "Seeing is Learning" cluster-randomized controlled trial. (in press).

Maul, E., Barroso, S., Munoz, S.R., Sperduto, R.D., \& Ellwein, L.B. (2000). Refractive error study in children: Results from La Florida, Chile. American Journal of Ophthalmology, 129(4), 445-454.

McKenzie, D., \& Rapoport, H. (2006). Can migration reduce educational attainment? Evidence from Mexico. Evidence from Mexico (June 1, 2006). World Bank Policy Research working paper. 3952.

Mo, D., Yi, H., Zhang, L., Shi, Y., Rozelle, S., \& Medina, A. (2012). Transfer paths and academic performance: The primary school merger program in China. International Journal of Educational Development, 32(3), 423-431.

Muñoz, B., West, S.K., Rodriguez, J., Sanchez, R., Broman, A.T., Snyder, R., et al. (2002). Blindness, visual impairment and the problem of uncorrected refractive error in a Mexican-American population: Proyecto VER. Investigative Ophthalmology E Visual Science, 43(3), 608-614.

Murthy, G., Gupta, S.K., Ellwein, L.B., Muñoz, S.R., Pokharel, G.P., Sanga, L., et al. (2002). Refractive error in children in an urban population in New Delhi. Investigative Ophthalmology E Visual Science, 43(3), 623-631.

Nilsson, J. (2007). The negative impact of amblyopia from a population perspective: Untreated amblyopia almost doubles the lifetime risk of bilateral visual impairment. British Journal of Ophthalmology, 91(11), 1417-1418.

Pi, L. -H., Chen, L., Liu, Q., Ke, N., Fang, J., Zhang, S., et al. (2012). Prevalence of eye diseases and causes of visual impairment in school-aged children in Western China. Journal of Epidemiology, 22(1), 37-44.

Provasnik, S., Kastberg, D., Ferraro, D., Lemanski, N., Roey, S., \& Jenkins, F. (2012, December 11). Highlights form TIMSS 2011 mathematics and science achievement of U.S. fourth and eighth-grade in an international context. Retrieved from http://nces.ed.gov/pubs2013/2013009_1.pdf

Ramke, J., Du Toit, R., Palagyi, A., Brian, G., \& Naduvilath, T. (2007). Correction of refractive error and presbyopia in Timor-Leste. British Journal of Ophthalmology, 91(7), 860-866.

Resnikoff, S., Pascolini, D., Mariotti, S.P., \& Pokharel, G.P. (2008). Global magnitude of visual impairment caused by uncorrected refractive errors in 2004. Bulletin of the World Health Organization, 86(1), 63-70.

Reynolds, C.R., \& Richmond, B.O. (1978). What I think and feel: A revised measure of children's manifest anxiety. Journal of Abnormal Child Psychology, 6(2), 271-280.

Saw, S. -M., Gazzard, G., Koh, D., Farook, M., Widjaja, D., Lee, J., et al. (2002). Prevalence rates of refractive errors in Sumatra, Indonesia. Investigative Ophthalmology E' Visual Science, 43(10), 3174-3180.

Saw, S. -M., Nieto, F.J., Katz, J., Schein, O.D., Levy, B., \& Chew, S. -J. (2000). Factors related to the progression of myopia in Singaporean children. Optometry E Vision Science, 77(10), 549-554. 
Sharma, A., Li, L., Song, Y., Choi, K., Lam, D., Zhang, M., et al. (2008). Strategies to improve the accuracy of vision measurement by teachers in rural Chinese secondary schoolchildren: Xichang Pediatric Refractive Error Study (X-PRES) report no. 6. Archives of Ophthalmology, 126(10), 1434-1440.

Smith, T., Frick, K., Holden, B., Fricke, T., \& Naidoo, K. (2009). Potential lost productivity resulting from the global burden of uncorrected refractive error. Bulletin of the World Health Organization, 87(6), 431-437.

Sperduto, R.D., Seigel, D., Roberts, J., \& Rowland, M. (1983). Prevalence of myopia in the United States. Archives of Ophthalmology, 101 (3), 405.

Tong, L., Saw, S. -M., Tan, D., Chia, K. -S., Chan, W. -Y., Carkeet, A., et al. (2002). Sensitivity and specificity of visual acuity screening for refractive errors in school children. Optometry \& Vision Science, 79(10), 650-657.

Wedner, S.H., Ross, D.A., Balira, R., Kaji, L., \& Foster, A. (2000). Prevalence of eye diseases in primary school children in a rural area of Tanzania. British Journal of Ophthalmology, 84(11), 1291-1297.

Wensor, M., McCarty, C.A., \& Taylor, H.R. (1999). Prevalence and risk factors of myopia in Victoria, Australia. Archives of Ophthalmology, $117(5)$, 658.

Wong, T.Y., Foster, P.J., Hee, J., Ng, T.P., Tielsch, J.M., Chew, S.J., et al. (2000). Prevalence and risk factors for refractive errors in adult Chinese in Singapore. Investigative Ophthalmology E' Visual Science, 41(9), 2486-2494.

World Health Organization (2006, October 11). Sight test and glasses could dramatically improve the lives of 150 million people with poor vision. Retrieved from http:/www.who.int/mediacentre/news/releases/2006/pr55/en/

World Health Organization (2012, June). Visual impairment and blindness. Retrieved from http://www.who.int/mediacentre/factsheets/fs282/en/

Xinhua (2011, November 16). New progress in development-oriented poverty reduction program for rural China. Retrieved from http://english.peopledaily.com.cn/ 102774/7647009.html

Yi, H., Ma, X., Zenf, J., Shi, Y., \& Rozelle, S. (2014). The role of teachers in providing vision care services: Teacher screening, glasses uptake and wear: Results from a randomized controlled trial in rural Chinese primary schools. REAP working paper.

Zhang, L., Kleiman-Weiner, M., Luo, R., Shi, Y., Martorell, R., Medina, A., et al. (2013). Multiple micronutrient supplementation reduces anemia and anxiety in rural China's elementary school children. Journal of Nutrition, 143(5), 640-647.

Zhao, J., Pan, X., Sui, R., Munoz, S.R., Sperduto, R.D., \& Ellwein, L.B. (2000). Refractive error study in children: Results from Shunyi District, China. American Journal of Ophthalmology, 129(4), 427-435. 